\title{
Exploring the use of films/dramas in giving awareness towards mental illness in society
}

\author{
Nor Mazlina Ghazali, Edris Aden, Azzahrah Anuar, Fatahyah Yahya, Anis Natasha Zulkifli \\ Program of Counselling, Faculty of Cognitive Sciences and Human Development, Universiti Malaysia Sarawak, \\ Malaysia
}

\begin{tabular}{l} 
Article Info \\
\hline Article history: \\
Received Mar 31, 2021 \\
Revised Jun 11, 2021 \\
Accepted Jun 23, 2021 \\
\hline
\end{tabular}

Keywords:

Awareness

Dramas

Film

Mental illness

Self-development

Society

\begin{abstract}
This study was exploring the use of films/dramas in giving awareness towards mental illness among society. Objective of this study was to explore the use of films in giving awareness on mental illness to the community. The study used qualitative research design. There were 11 participants of this study which consisted of three stages of human development (adolescent, early and late adulthood). They also come from varies background such as different work setting, age, occupation as well as level of education. The varies background among participants were provided different answers of questions. The method of data collection was an interview with semistructured questions. Analysis of data using Thematic Analysis. Findings showed few themes have been found from the interview such as personality of participants that lead them to watch this type of films/dramas, effect after they watched this type of films/dramas, perception of participants towards mental illness films/dramas, learning process and suggestion to improve this type of films/dramas in Malaysia. The implication of this study, participants gaining more awareness on mental illness after watching type of films/dramas. They also found this genre of films/dramas enable to educate them to be open with people who suffer from mental illness. In conclusion, future researcher can explore the effect of watching mental illness genre films/dramas towards self-development among society.
\end{abstract}

This is an open access article under the CC BY-SA license.

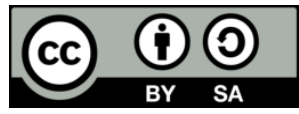

\section{Corresponding Author:}

Nor Mazlina Ghazali

Program of Counselling

Faculty of Science Cognitive and Human Development

Universiti Malaysia Sarawak, Malaysia

Email: gnmazlina@unimas.my

\section{INTRODUCTION}

The mental illness becomes the second biggest health problem affecting Malaysians after heart disease [1]. It is showed the uprising number of people who suffered from mental illness. Moreover, some of society have stigma towards people who have mental illness. Stigma is caused by the worse condition of people with mental illness. So, the mental illness has to treat well by society to support them. There is platform like social media, seminar, conference, forum, poster, media or campaign regarding mental illness. The purpose of this platform is for spreading-awareness and information towards society [2]. Current studies showed the social media use to promote mental health and wellbeing. Then, social media, it is also potentially to promote the intervention on mental health [2].

The film has become an influential medium to the community [3]. The mental illness health in a film can have a significant impact on the public's views on mental illness, and consequently on how people with mental health problems are considered and treated [4]. 
In previous history, mental illness is become depicted as negative in popular cinema and film has been described as "a reservoir of prejudice, ignorance and fear that feeds and perpetuates damaging stereotypes of people with mental health problems" [5]. However, the film has also been shown to be a useful tool in learning about mental health and mental illness [6]. This showed the film play an important role in assisting the community to understand-mental illness. Other than that, there is evidence showed the mental health problem is difficult to discuss. However, this enables to solve using the film which allows engagement in a "once-removed" way [7].

Several studies have explored the use of film for teaching medical students about mental health disorders as part of the undergraduate curriculum [8]. Apart from that, previous study [9] explored the use of film to the same end through an extracurricular film club. Film has also been explored for its use with patients as an aid to therapy [10]. The way film used as a tool to explore the mental illness among patient become significant for studies in medical.

There is a contradiction idea by Izod and Dovalis [11], which found out the difficulties to engage deeply with the emotional experience of film in any setting other than cinema. In cinema, the audience has a conducive environment to immerse with the content of the film. In several medical studies, they create an environment like cinema to obtain similar reflection of emotions among audience toward mental illness story.

Cinema and film have been described as the most influential form of media [12]. Thus, it gives a serious problem for those that experiencing mental illness [13]. In addition, the mass media included newspapers. Televisions and movies may give an important source of information about mental illness for laypeople. However, mass media also may give a depiction of mental illness compared to physical illness [14].

Moreover, psychological and psychiatric topic has been popular in the mass media for a long time such as magazines, radio, newspapers, television and fictional literature [15]. Thus, most of the film is often faced with presentation of mental illness as their theme of film [16]. In addition, a previous study was stated that there is a socialising effect on exposure to television such as give influence for audience perception of reality [17]. Hence, these effects of watching the mental illness theme of film may give effects of violence.

As cited in [16] mental illness is superficial, stereotypical and downright wrong in mass media such as film. Normally, a film that related to mental illness may overemphasize negative aspects to the audience [17]. This is because mental illness is normally shown displaying violent and bizarre behaviour. These were supported by Dienfenbach and West [18], characters that related to mental disorder on mass media may portrayed as brutal criminals than characters without mental disorders. Previous study was stated that a popular primetime drama and discovered that mental illness was used frequently to explain the reason a character has committed a crime.

In addition, people that have been watching a movie that related to crime, violent or mentally ill characteristics will perceive mental disorder more negatively than people that watched a movie with a genre not related to mental illness [19]. Thus, the more time people watching television, the more they will perceive the mental illness as inferior to mental health [20]. The longer time people spent their time to watch psychological genre of film will less their tolerant toward a person with mental illness [20]. However, people that have the ability to differentiate between non-fiction and fiction may have more positive feelings towards person that suffer from mental disorder [21]. Hence, the audience will form their own beliefs and attitudes and tend to develop negatives perceptions toward mental disorder.

Stigma is a problem that consists of knowledge, attitudes and behaviours that may lead to ignorance, prejudice and discriminations [22]. Thus, stigma was normal in all societies and may damage the well-being of people that suffer from mental illness [23]. This is similar to previous study, the manners from people to deal with mental illness may reflect and enshrined by mental health policy by direct and indirect effect for those who suffer from mental illness [24].

In addition, a stigmatised person may be viewed as not quite human and may reduce to a tainted individual [25]. Hence, stigma may give a negative effect on the lives of people with mental illness including prejudice and discrimination [26]. This may lead to self-stigma which is people that suffer from mental illness may judge themselves from their own experiences, negative social reaction and perception [27]. The judgement may decrease their self-esteem as a person because they may feel not good enough to live the expectation from others [28].

Based on a previous study, stigma is a process that may involve the recognition of cues from people with mental illness, the activation of stereotypes, and lastly the discrimination and prejudice against that person [29]. Firstly, a cue is a social cognitive process that involves recognition from variety of people. For instance, people diagnosed with mental illness have more stigma than normal people [27]. The second is the activation of stereotypes. After people have been cued, the stereotype may be activated within these processes. The definition of stereotype is the knowledge is learned by a social group [28]. Stereotype is collectively agreed by a group of people that have similar knowledge and used to categorise these people 
[30]. Thus, stereotypes may lead to prejudice. Prejudice was defined as a result of cognitive and affective from the stereotypes. A fear of contamination and overwhelming to avoid the judgement as unacceptable or offensive [31].

Moreover, stigma was impeding recovery by eroding an individual's social status, behaviour, social network and self-esteem that may lead to poor outcomes, negative behaviour and low self-esteem including unemployment, isolation, delayed treatment-seeking, treatment-refractory symptoms, prolonged course and avoidable hospitalisations [22]. These may impose by other expectations that individuals with mental illness are unable to live up to the responsibility that is part of everyday living [28].

Total contact may increase the perception of danger and attempts to keep social distance decrease [32]. This is because personal contact with a stigmatised group may have stigmatising attitudes [33]. Thus, minimal contact with someone that has a mental illness may change the stigmatising beliefs [32]. Furthermore, the stigmatised group has a different perception of group [34]. For instance, an individual with someone that has mental illness may consider as typical of a stereotype that shows reinforce of stereotypes [35].

Stigmatising these issues is the psychological point of impact of society on the person's experience with mental illness. Regardless of an individual's history of discrimination experiences or beliefs about how society views the mentally ill, the degree to which one's morale is affected by stigma may be amenable to change.

\section{RESEARCH METHOD}

The study used qualitative research design. The aim of qualitative research is the systematic development of theory by a thorough inspection of social reality. Starting with a roughly defined theoretical framework (often in the form of a set of sensitising concepts), the researcher continuously tries to confront this framework with the field under observation to specify, define and ground these concepts and to formulate a substantive social theory [36]. The researcher used the phenomenological type of design in this study. Exploration of the use of films/dramas in giving awareness of mental illness among community.

\subsection{Sampling technique}

This study used purposive sampling. This method is also known as subjective sampling which participants have been chosen purposely to answer the questions of interview. The inclusivity criteria of participants determined by researcher judgement who are going to involved in the study [37]. Participants are categorized into three group based on human development stages which are adolesecent, early adulthood and late adulthood. Participants have to be someone who is watched the films/dramas especially in mental health genre. Those who are not watching mental health films/dramas cannot be participants. Besides, this study is also not considerated the similar type of mental illness that presented in films/dramas. Researcher is only focused on the awareness that gained by participants from watching the films/dramas.

\subsection{Data collection}

Data is obtained from participants who are divided into three stages of human development adolescent, early adulthood and late adulthood. Participants are from age 19 to 49 were included three stages of human development. Answers from participants are assumed to represent the ideas from the level of stages. Other than that, the inclusion criteria of this study are participants have to be someone who is experienced in watching films/dramas related to mental illness. Researcher is not limiting the type of mental illness that participants watched in films/dramas. This is enabled researcher to obtain vague ideas from participants. Depth ideas from participants may increase the information on study matter.

\subsection{Interview protocol}

The study used a semi-structured interview. The interview protocol has been checked with peers. Questions are covered few components such as demographic, types of mental illness, personality (what make you watch the films/dramas of this genre, what is your favourite films/dramas, are you voluntary to watch this type of films/dramas and what is another type of films/dramas that she/he like to watch), effect and learning process after watching the films/dramas as well as the improvement that films/dramas maker need to do in this type of genre of films/dramas (do you understand about mental illness after watching the films/dramas, what have you learn after watching the films/dramas, do you able to explain about mental illness after this, do you think society need to watch this type of films/dramas, from your point of view how to improve the films/dramas in order to ensure more society watch and understand about mental illness. 


\subsection{Data analysis}

In this study, researcher used thematic analysis in analyzing the data. Thematic analysis can be defined as a method in an application set of texts for instance details of interview transcribing [38]. In thematic analysis it is involved familiarization, coding, generating themes, and reviewing themes, defining and naming themes and writing up. Through this process, the researcher has obtained details on themes from interviews.

\section{RESULTS AND DISCUSSION}

Result of this study is divided into demographic and themes from the interviews. Themes listed are types of mental illness, personality, effect after watching the films/dramas, perception and personal reflection.

\subsection{Demographic}

From the 11 participants, three of them which are $27.3 \%$ from late adulthood while six participants are early adulthood at $54.5 \%$ and two of them which is $18.2 \%$ are adolescent. This is explained in Table 1.

Table 1. Stage of human development among participants

\begin{tabular}{ccc}
\hline Stage & Frequency $(\mathrm{n})$ & Percentage $(\%)$ \\
\hline Late adulthood & 3 & 27.3 \\
Early adulthood & 6 & 54.5 \\
Adolescent & 2 & 18.2 \\
\hline
\end{tabular}

Table 2 is describes the frequency of participants on watching films/dramas related to mental illness genre. Adolescent participants showed the frequency at weekend, twice a week, and four times a week. Hence, the early adulthood stated the frequency of watching the films/dramas is less than one hour per day, twice a week, every day, once a week, often and once a day. Besides, the late adulthood frequently watches approximately every week and once a day. In conclusion, the majority of participants are watching films/dramas in this genre at least once a day.

Table 3 shows the marital status of participants. Majority of them are singles and only four are marriage. So, since the majority of participants are single the frequency of watching films/dramas also high. The occupation of participants is from varies field such as students, graduate research assistant, office worker, admin and account assistant, lecturer and housewife. The varies field of occupation among participants is enabled to provide a variety of information on content.

Table 4 is describes the occupation of participants. Majority of participants are students, followed by other occupations such as graduate research assistant, office worker, administrative and account assistant and housewifes. Table 5 describes the division of gender of the participants. Only one participant is male and the other ten is female are become majority in this study. It is perhaps, females have more tendencies in watching this type of films/dramas.

Table 2. Frequency on watching films/dramas

\begin{tabular}{ccc}
\hline Stage & Participants & Frequency \\
\hline \multirow{2}{*}{ Adolescent } & P01 & Weekend \\
& P02 & Twice a week \\
& P03 & Four times per week \\
& P04 & Less than one hour per day \\
Early adulthood & P05 & Twice a week \\
& P06 & Everyday \\
& P07 & Once a week \\
& P08 & Often \\
Late adulthood & P09 & Once a day \\
& P10 & Every week \\
& P11 & Once a day \\
\hline
\end{tabular}

Table 3. Marital status of participants

\begin{tabular}{ccc}
\hline Stage & Name & Status \\
\hline \multirow{2}{*}{ Adolescent } & P01 & Single \\
& P02 & Single \\
& P03 & Single \\
& P04 & Single \\
Early adulthood & P05 & Single \\
& P06 & Single \\
& P07 & Single \\
& P08 & Married \\
Late Adulthood & P09 & Married \\
& P10 & Married \\
& P11 & Married \\
\hline
\end{tabular}

Table 4. Occupation of participants

\begin{tabular}{ccc}
\hline Stage & Name & Occupations \\
\hline \multirow{2}{*}{ Adolescent } & P01 & Student \\
& P02 & Student
\end{tabular}




\begin{tabular}{ccc} 
& P03 & Student \\
& P04 & Graduate research assistant \\
Early adulthood & P05 & Student \\
& P06 & Office worker \\
& P07 & Student \\
& P08 & Admin and account assistant \\
Late adulthood & P09 & Lecturer \\
& P10 & Housewife \\
& P11 & Housewife \\
\hline
\end{tabular}

Table 5. Gender of participants

\begin{tabular}{cc}
\hline Gender & Frequency \\
\hline Male & 1 \\
Female & 10 \\
\hline
\end{tabular}

\subsection{Type of mental illness in film/dramas}

Participants state several types of mental illness that they obtained during watched the films/dramas. Type of mental illness mentioned by participants are personality disorder, depression, bipolar disorder, narcissistic, manic disorder, dissociative identity disorder (DID), anxiety, burnout, post-traumatic stress disorder (PTSD), postpartum depression, anti-social disorder, and schizophrenia. Type of mental illness is listed in Table 6. In summary, participants had gained awareness on type of mental illness after watched the film/dramas that carried the genre.

Table 6. Type of mental illness in films/dramas

\begin{tabular}{|c|c|c|}
\hline Stage & Name & Type of mental illness \\
\hline \multirow{12}{*}{ Adolescent } & P01 & Personality disorder \\
\hline & P02 & Depression \\
\hline & P03 & Bipolar disorder \\
\hline & & Narcissistic \\
\hline & & Manic disorder \\
\hline & P04 & Dissociative identity disorder (did) \\
\hline & P05 & Bipolar disorder \\
\hline & & Narcissistic \\
\hline & & Manic disorder \\
\hline & & Dissociative identity disorder (did) \\
\hline & P06 & Dissociative identity disorder \\
\hline & & Onset of depression \\
\hline \multirow[t]{12}{*}{ Early adulthood } & & Anxiety \\
\hline & & Burnout \\
\hline & & Post-traumatic stress disorder (ptsd) \\
\hline & & Postpartum depression \\
\hline & & Anti-social disorders \\
\hline & & Narcissistic \\
\hline & P07 & Antisocial personality disorder \\
\hline & P08 & Schizophrenia \\
\hline & & Bipolar disorder \\
\hline & & Personality disorder \\
\hline & & Dissociative identity disorder \\
\hline & P09 & Personality disorder and he suffered from severe physical abuse. \\
\hline \multirow[t]{2}{*}{ Late adulthood } & $\mathrm{P} 10$ & Personality disorder \\
\hline & P11 & Bipolar disorder \\
\hline
\end{tabular}

\subsection{Personality of participants}

Participants of this study state they are watching the films/dramas is because this genre of films/dramas look interesting, aware of this mental illness, to know the causes and effects, the unexpected story plot, to watch the character's personality, gain new knowledge, to gain experience and insight on how individual suffering mental disorder live in daily life and their history. Other than that, participants who are watching this type of films/dramas because they would like to watch the reality of the people that have mental illness. Participant also states that watching films/dramas to fulfil the time. Below is the citation from participants; 
"The unexpected plot, the mystery and want to know how the movie portrayed the mental illness." (Participant 04)

"To gain experience and insight on how individual suffering mental disorder live in daily live and their history." (Participant 07)

Participants also mentioned their favourite films/dramas are Anomalisa, The Originals, The Split, Joker, Forgotten, Kim Ji Young born and its okay not to be okay. However, there are three of participants have not stated their favourite films/dramas. All participants mentioned they are voluntarily watching the films/dramas.

\subsection{Effect and learning process after watching the films/dramas}

Most of the participants stated that they are gaining awareness after they watched the films/dramas. They gain a little insight on how people with such mental health conditions act and behave. A participant mentioned she is doubting on people with mental illness behave and how they committed criminals. Besides, the participant also mentioned her gain information on reason of people who are suffered from mental illness.

"Yes, I gain a little insight on how people with such mental health conditions acts and behave." (Participant 03)

"Yes, but in doubt is it really how DID people will behave and why mental illness movies are always related to criminals." (Participant 04)

Based on research finding, participants have learnt something after watched the films/dramas that content mental illness. Participants mentioned that they are aware that each of the people had their own problem. People who face difficulties one faces when they are depressed, certain mental health issue such as manic came as a result from history of abuse and participants aware that the origin of the mental illness stems from childhood when they grow. Other than that, participant also learnt the suffers and nightmare of people with mental illness, different way of thinking, miss communication and hard to be understand. Thus, people surround them must seek knowledge to handle people with mental illness. Participant also learned that everything that happens in life has to share with someone else. The participant gain awareness that those who are suffering from mental illness is caused from family problem.

In addition, five participants mentioned that they are able to explain mental illness after they watched the films/dramas. However, six of them mentioned they not really sure if they are able to explain related to mental illness. They are able to explain a little bit of mental illness after they watch the films/dramas with complimentary support reading material. Below is citation from participants;

I will give my rating to this question 6/10. Because mental illness that showed in this drama is just the surface and sometimes does not show the true story of individual with mental illness, another $4 / 10$ can be gain from self-reading and research about the illness scientifically. (Participant 07)

.....To explain in professional term, I am not expert to explain. However, I am understand about mental illness. (Participant 08)

Based on the finding, the participants described the society should watch that type of genre films/dramas in order to educate and giving awareness to them. Participant says that partly yes, but it may not show the true representation of mental illness and just create a stigma for people to be afraid of them. In addition, the participant describes through films/dramas society is being educated wisely.

.....Yes, because currently there are so many cases but people think it just not important issues. Then, people usually accuse each other and not realize the main reason of the mental illness. This is because some family don't want 'crazy" in their family.... (Participant 11)

\subsection{Elements that can be improved in the films/dramas that you watch}

Participants shared their point of view on how to improve the films/dramas in order to ensure more society watch and understand about mental illness. Participants describe that the film should be in multiple languages and straight to the point, the way actor shows the character should be appropriate and presentation should not be too heavy to understand, do not always relate to criminals it might be some happy ending or based on a true story, our film industry more open about this type of genre and do a lot of research before produce any film regarding mental illness. This is because, by doing research, the producer may have a 
different view and extra knowledge about mental illness. Thus, the film will become more quality and can educate people about mental illness. Thus, improving film or drama marketing, casting the most influential actors or actresses in drama or film. Using easy term (not specified medical term) for a public audience, drama and film should be what audience can relate and mostly happen in their daily life.

......At the end of the film, producer should suggest and show in details on how to support and help mental illness people as well do not judge them.... (Participant 09)

.....Made a lot of film with this genre. However, our community (Malay), are usually do not interest with this kind of film because don't want to think further and more prefer a leisure movie. Also, Malaysian film usually don't have this kind of film. Hence, it will be nice, if film industry can be collaborating with government bodies to give awareness to community. It much easier if we can get any sponsor to help film industry to produce a lot of film with this genre. Other than that, we can see social media as the main platform to give awareness such as YouTube.... (Participant 11)

They also described that films/dramas in this genre need to put some disclaimer. Some plot that helps the person cure or any intervention that successfully took place. How the community can help without feeling scared of being hurt. Participant also stated that the producer can enhance the films/dramas into real-life.

.......May put some disclaimer. Some plot that helps the person cure or any intervention that successfully took place. How the community can help without feeling scared of being hurt.... (Participant 04)

Participants stated the producer has to use suitable content to avoid individual that might trigger scenes in the films. In addition, the producer also needs to use the right research and content to educate people about this genre. The producer also should highlight how society can handle individual with mental illness with care. Other than that, producer also can highlight the causes on how mental illness happens and the history to give awareness to society. Participant also suggests the producer has to upgrade knowledge and awareness among audiences. The element of improvement is useful for the producer to empower and enhance their content of films/dramas in order to educate society about mental illness.

.....They must improve in the content of knowledge and awareness for the audience.... (Participant 10)

\section{DISCUSSION}

Participants describe they watch the films/dramas because it is looking interesting, they aware of this mental illness and to know the causes and effects, story of plot and to watch the characters of the personality. Other than that, the participants enable to gain experience and insight on how individual suffering mental disorder live in daily life and their history. This is synchronous with a study by [39], which stated the cinema can become therapy and catalyst for improvement in term of visual, plot, image, and music. This type of genre is enabled to provide insight, inspiration, emotional release and genuine improvement. All participants know their favourite films/dramas that related to mental illness plot of story. These findings showed the participants are obtained a positive personality towards gaining knowledge and information related to mental illness.

Therefore, participants also experienced the effect after they watched the films/dramas. Finding showed the participants understand about mental illness after they watched the films/dramas. They gain a little insight on how people with such mental health conditions act and behave. Understanding mental illness will reduce prejudice and stigma among society. Interactions with media can provide awareness to society in order to reduce stigma, barriers, conveying the safety or efficacy [40]. Then, participants also describe they start to understand the reason why people suffered from mental illness. According to [41], their study found the training programs provided toward pharmacist students is enabled to reduce their social distance and attitudes towards people who suffers from mental illness. The study also found the pharmacist students have a high level of stigmatizing on people with mental illness type schizophrenia. So that, through films/dramas society will gain awareness in an easy way.

Through films/dramas, participants also mentioned they learn to know the type of mental illness. They also learn to understand the character and behaviour of people who suffers with mental illness. Participants also learn to understand the nightmare of people who suffers with mental illness. Other than that, the participants also learn to observe the behaviour of people with mental illness who are defensive and aggressive. Then, the participant also learns how the importance of parents to be good to children. The 
finding of this study has been supported with other research by Till et al. [19], their study showed the results which films/dramas have a strong impact on the emotional and cognitive state of the viewers. Finding from this study, also described that they have confidence to explain briefly on the mental illness. Other than that, the participants state the films/dramas are become the platform for society to gain awareness towards mental illness. As technology keeps growing, political and economic leaders have utilized cinema in changing and shaping people's outlooks either for their benefit or for the benefit of the people. Society will learn something when they watch the films/dramas however the content of that should represent the true story of the situation of mental illness. The successful of films/dramas determine by the quality of the content [42].

\section{CONCLUSION}

In conclusion, majority participants of this study are female. They are come from varies background of occupation which provide different point of view related to the topic of study. Other than that, different developmental stage of participants contributed different ideas and perspectives. Those who are from early and late adulthood showed the details understanding and awareness towards mental illness condition. For adolesecent they are mentioned limited understanding and awareness to the issue.

Discussion on content that obtained from participants are surrounded with type of mental illness use in films/dramas, effect and learning process after watching this type of genre and details of elements that can be improves by film maker or producer in films/dramas that they produced. Type of mental illness mentioned by participants are personality disorder, depression, bipolar disorder, narcissistic, manic disorder, dissociative identity disorder (DID), anxiety, burnout, post-traumatic stress disorder (PTSD), postpartum depression, antisocial disorder, and schizophrenia. Besides, the participants gain positive effect after they watched the films/drams in this genre. They developed more knowledge related to the mental illness. Then, they also learn to understand more on people who suffers with mental illness through the films/dramas as well as how people with mental illness struggle with coping and adjustment for being functioning in society. From this study, the suggestion for future researcher is recommended to explore the effect of watching mental illness genre films/dramas towards self-development among society.

\section{ACKNOWLEDGEMENTS}

Thank you to Universiti Malaysia Sarawak for sponsor my research under $\mathrm{P}$ Ramlee Chair F04/PRC/1954/2020 and to all my team members for the collaboration.

\section{REFERENCES}

[1] National Health and Mobidity Survey, "Institute for Public Health," 2020. [Online]. Available: http://iku.moh.gov.my/nhms-2020.

[2] Naslund J.A, Bondre A., Torous J., and Aschbrenner, K. A, "Social Media and mental health: Benefits, risks, and opportunities for research and practice," Journal of Technology in Behavioral Science, vol. 5, no. 3, pp. 245-257, 2019.

[3] Goodwin G. P., Piazza J., and Rozin P, "Moral character predominates in person perception and evaluation," Journal of Personality and Social Psychology, vol. 106, no. 1, pp. 148-168, 2014, doi: $10.1037 / \mathrm{a} 0034726$

[4] Darbyshire D and Baker P, "A systematic review and thematic analysis of cinema in medical education," Med Humanities, vol. 38, no. 1, pp. 28-33, 2012, doi: 10.1136/medhum-2011-010026

[5] Byrne P., "Stigma of mental illness and ways of diminishing it," Advances in Psychiatric Treatment, vol. 6, no. 1, pp. 65-72, 2000.

[6] Wedding D and Niemiec R.M., "The clinical use of films in psychotherapy," Journal of Clinical Psychology, vol. 59, pp. 207-215, 2003.

[7] Raingruber B., "Video-cued narrative reflection: A research approach articulating tacit, relationsl, and embodied understandings," Qualitative Health Research, vol. 13, no. 8, pp. 1155-1169, 2003.

[8] Friedman S. and Hall R.CW, "Using Star Wars' supporting characters to teach about psychopathology. Australasian Psychiatry, vol. 23, no. 4, pp. 432-434, 2015, doi: 10.1177/1039856215590032.

[9] Webster C.R., Valentine. L.C., and Gabbard G.O., "Film clubs in psychiatric education: the hidden curriculum," Academic Psychiatry, vol. 39, no. 5, pp. 601-604, 2015, doi: 10.1007/s40596-014-0252-2.

[10] Lampropoulos G, K., Kazantzis N., and Deane F. P., "Psychologists' use of motion pictures in clinical practice," Professional Psychology: Research and Practice, vol. 35, no. 5, pp. 35-541, 2004, doi: 10.1037/07357028.35.5.535

[11] Izod J. and Dovalis J., "Cinema as therapy: Grief and transformational film," Routledge Taylor and Francis eBooks: UK, 2015.

[12] Damjanovic A., Vukovic O., Jovanovic A.A. and Jasovic-Gasic M, "Psychiatry and movies," Psychiatry Danubina, vol. 21, no. 2, pp. 230-235, 2009. 
[13] American Psychological Association, "Mental health issues increased significantly in young adults over last decade," 2019. [Online]. Available: https://www.sciencedaily.com/releases/2019/03/190315110908.htm

[14] Moise D. and Madhusoodanan S., "Psychiatric Symptoms Associated with Brain Tumors: A Clinical Enigma," CNS Spect, vol. 11, no. 1, pp. 28-31, 2006.

[15] Schwarz N., "Self-reports: How the questions shape the answers," American Psychologist, vol. 54, no. 2, pp. 93105,1999

[16] Harper S., "Understandiing mental distress in film and media: A new agenda?," Perspectives in Public Health, vol. 128, no. 4, pp. 170-174, 2008.

[17] Morgan M. and Shanahan J., "The state of cultivation," Journal of Broadcasting and Electronic Media, vol. 54, no. 2, pp. 337-355, 2010.

[18] Dienfenbach D. L and West M. D, "Television and attitudes toward mental health issues: Cultivation analysis and the third-person effect," Journal of Community Psychology, vol. 35, pp. 181-195, 2007.

[19] Till B., Niederkrotentthaler T., Herberth A., Voracek M., Sonneck G., and Vitouch P., "Coping and film reception: A study on the impact of film dramas and the mediating effects of emotional modes of film reception and coping strategies," Journal of Media Psychology Theories Methods and Applications, vol. 23, no. 3, pp. 149-160, 2011.

[20] Granello D. H and Pauley P. S, "Television viewing habits and their relationship to tolerance toward people with mental illness," Journal of Mental Health Counselling, vol. 22, no. 2, 162-175, 2000.

[21] Livingston J. J, and Boyd J. E, "Correlates and consequences of internalized stigma for people living with mental illness: a systematic review and meta-analysis," Social Science Med., vol. 71, no. 12, pp. 2150-2161, 2010.

[22] Struening E.L, Perlick D, Link B. G, and Hellman F., "Stigma as a barrier to recovery: The extent to which caregivers believe most people devalue consumers and their families," Psychiatric Services, vol. 52, no. 12, pp. 1633-1638, 2001.

[23] Ahmedani B.K, "Mental Health stigma: Society, individuals and the profession," Journal of Social Work Values Ethics, vol. 8, no. 2, pp. 4-16, 2011.

[24] Link B. G, Struening E, Neese-Todd S., Asmussen S., and Phelan JC, "Stigma as a barrier to recovery: The consequences of stigma for the self-esteem of people with mental illnesses," Psychiatric Services, vol. 52, no. 12, pp. 1621-1626, 2008.

[25] Goffman E., Stigma: Notes on the Management of Spoiled Identity, Englewood, Cliffs NJ: Prentice Hall, 1963.

[26] Hinshaw S.P. The mark of shame: Stigma of mental illness and an agenda for change, Oxford: University Press, 2007.

[27] Krueger J, "Probalistic National stereotypes,” European Journal of Social Psychology, vol. 26, no. 6, pp. 961-980, 1996.

[28] Emler N., "Self esteem: The cost and causes of low self-worth," York Publishing Services, 2021.

[29] Corrigan P.W .and Watson A.C, "Understanding the impact of stigma on people with mental illness," World Psychiatry. 1: 16-20, 2002.

[30] Corrigan P. W et al., "Three strategies for changing attributions about severe mental illness," Schizophrenia Bulletin, vol. 27, no. 2, pp. 188-195, 2001.

[31] Alexander L. A and Link B. G, "The impact of contact on stigmatizing attitudes toward people with mental illness, Journal of Mental Health, vol. 12, no. 3, pp. 271-289, 2003.

[32] Ingamells S., Goodwin A. M. and John C., "The influence of psychiatric hospital and community residence labels on social rejection of the mentally ill," British Journal of Clinical Psychology, vol. 35, no. 3, pp. 359-367, 1996.

[33] Couture S. M. and Penn D. L. "Interpersonal contact and the stigma of mental illness: A review of the literature," Journal of Mental Health, vol. 12, no. 3, pp. 291-305, 2003.

[34] Reinke R. R., Corrigan P. W., Leonhard C., Lundin R. K., and Kubiak M. A, "Examining two aspects of contact on the stigma of mental illness," Journal of Social and Clinical Psychology, vol. 23, no. 3, pp. 377-389, 2004.

[35] Wester F.P.J., and Peters V., "Qualitative analysis: Phases, techniques and computer use," Studies in Qualitative Methodology, vol. 6, pp. 139-164, 2018.

[36] Dudovskiy J., "Research methodology," 2018. [Online]. https://research-methodology.net/researchmethodology/research-types/

[37] Craulfield J., "How to do thematic analysis," 2019. [Online]. Available: https://www.scribbr.com/methodology/thematic-analysis/

[38] Singer J., "How watching movies can benefit our mental health," Medically Reviewed by Scientific Advisory Board, 2018. [Online]. Available: https://psychcentral.com/blog/how-watching-movies-can-benefit-our-mental-health\#1

[39] Sagar R, "Media potrayal of mental illness: role and responsibilities of Psychiatrists," Journal of Mental Health and Human Behaviour, vol. 17, pp. 91-94, 2012.

[40] Bamgbade B.A, Ford K.H and Barner J.C, "Impact of a mental illness stigma awareness intervention on Pharmacy student attitudes and knowledge," American Journal of Pharmaceutical Education, vol. 80, no. 5, pp. 1-11, 2016.

[41] Reich J., Exploring movie construction and production: What's so exciting about movies, Genesee Community College: SUNY, 2017. 